\title{
Row over fate of endangered monkeys
}

\section{David Cyranoski, Tokyo}

Japanese researchers and animal-welfare activists are at loggerheads - again - over the treatment of wild monkeys that are captured, sold to laboratories and used for research in neuroscience and physiology.

The country's Environment Agency is preparing new guidelines on the treatment of Japanese macaques, for implementation in the new year. But neither researchers nor activists are happy with the agency's draft, which is open for public comment until 17 November.

The use of macaques in research is a longrunning bone of contention in Japan (see Nature 393, 404; 1998). Although, as an endangered species, they are not on the list of animals that can be hunted, the monkeys can wreak havoc in farming communities, and

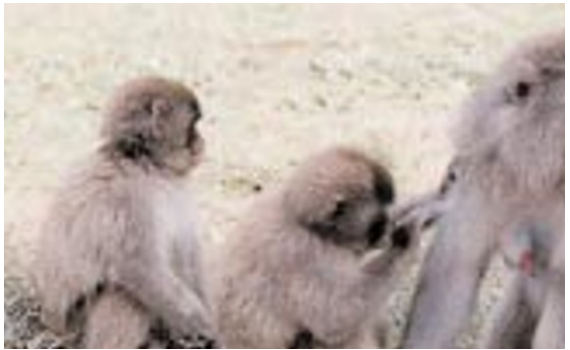

Look out: the law aimed at protecting Japan's threatened macaques is under discussion again.

local governments grant permission to 'remove' them when a damage claim is submitted. More than 53,000 have been collected in this way since 1993.

Problems arise after the monkeys are caught. Legally, those who capture monkeys

\section{Fake finds reveal critical deficiency}

Last week's disclosure of extensive fraud by one of Japan's leading archaeologists has led to renewed soul-searching about how much the nation's more prominent scientists are allowed to escape criticism by their peers.

The self-examination began after journalists from Mainichi Shimbun, one of Japan's leading newspapers, twice filmed Shinichi Fujimura burying stone tools he had collected in previous archaeological digs, to unearth them again as prehistoric records. Archaeology is a national obsession in Japan, and Fujimura's 'discoveries' had often made front-page news.

Fujimura - who, according to critics, had no advanced degree and little scientific training - was last week sacked from his post as senior director of the Tohoku Paleolithic Institute. The episode has raised questions about a scientific culture that allowed Fujimura's work to continue, and to be taken seriously, despite suspicions that, it

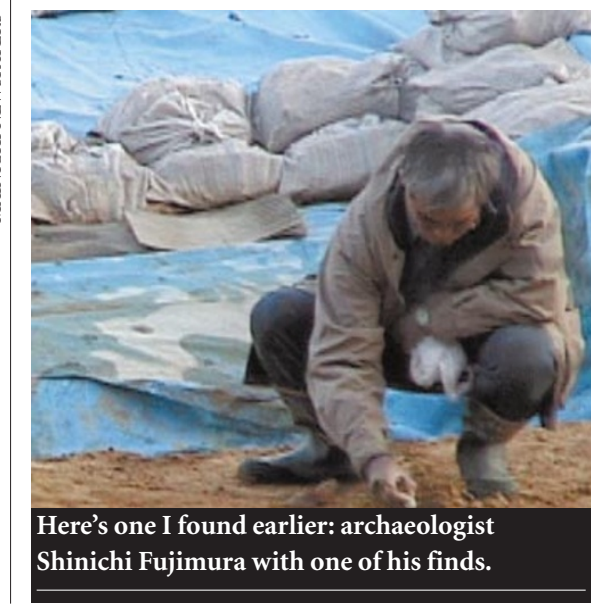

now emerges, stretched back many years.

"In Japan, it is hard to criticize people directly, especially those in established positions, because the critique is taken as a personal attack," explains Hisao Baba, a palaeoanthropologist at the National Science Museum in Tokyo. He hopes this episode will help usher in a culture of research in which criticism is accepted at a scientific rather than a personal level.

The problem has been widely noted in Japan. A visiting physicist, for example, confided that he felt pressure to tone down research that overturned a leading Japanese physicist's findings as it would have been considered a "personal insult".

According to Shizuo Oda of the Tokyo Metropolitan Division of Cultural Affairs, this soft-pedalling can make researchers as limited in their views as " $a$ frog in a well that is unaware of the ocean". Academics may not care about other researchers' work, or about having their own work peer-reviewed. This is especially dangerous in an archaeological community where, Oda says, intuition is sometimes valued over facts.

Fujimura claims that all the work he did before the filmed forgery was authentic. But most Japanese archaeologists are waiting for the rest of his findings to be discredited. Several archaeologists and anthropologists are now saying that Fujimura's discoveries did not mesh with other information about the sites. His discoveries suggested that the Japanese Stone Age stretched back as far as 700,000 years ago. But Oda has long held

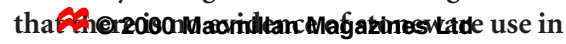
Japan before about 50,000 years ago. D. C. must report only how many they have taken. Monkeys are either killed, put in a preservation park, or sent to research facilities.

According to the animal-protection group ALIVE (All Life in a Viable Environment), between 1,000 and 2,000 macaques end up in laboratories each year. In one case, a local government sent monkeys to a nearby medical school, but claimed to have put them in a preservation park. The transfer itself is not illegal, but misrepresenting the destination is.

"Although the exact legal framework to punish such violations is unclear, such cover-ups are an acknowledgement of lawbreaking," says ALIVE spokesman Fusako Nogami, adding that animals taken in this way should be off-limits for research.

The Japanese Society for Primate Research says that removed monkeys should be put down rather than used for medical research. But other scientific societies want the animals to be used in research. They claim that researchers follow strict guidelines on the care and testing of animals, in line with international standards.

The Environment Agency's draft is not legally binding, but it is likely to influence the application of binding laws, and is therefore being hotly debated.

The draft's most controversial phrase states that the monkeys may be used for "research on the ecology or health of the monkeys themselves". Researchers fear that such a suggestion, along with pressure from animal-rights groups, will persuade judges to restrict research to this single case. They say that another proposal, requiring applications for removal to state the monkeys' fate after capture, would discourage local governments from giving macaques to research.

A representative for the Japan Neuroscience Society predicts that the supply of macaques would fall, raising their price from an affordable $¥ 150,000$ (US\$1,400) to a prohibitive $¥ 1$ million. This, he says, would make research impossible for all but a few of the 40 or so laboratories currently working with monkeys.

The representative says that the Environment Agency's proposal underestimates the importance of the research, without which, he says, "we would know nothing about the human brain". He considers that the guidelines should endorse the use of macaques in research.

Nogami counters that the removal of macaques is used to justify what has become a systematic procurement of monkeys for research. Since the World Conservation Union lists Japanese macaques as endangered, she adds, the guidelines should prohibit their use and lay out clearer rules for the punishment of transgressors. 